Article

\title{
Um Estudo de Focos de Calor no Bioma Caatinga e suas Relações com Variáveis Meteorológicas
}

\author{
José Maria Brabo Alves $^{1}$ (D), Emerson Mariano da Silva ${ }^{1}$ (D), Francisco Carlos de Araújo ${ }^{1,2}$, \\ Lindenberg Lucena da Silva ${ }^{3}$ \\ ${ }^{1}$ Mestrado Profissional em Climatologia e Aplicações nos Países da CPLP e África, Universidade \\ Estadual do Ceará, Fortaleza, CE, Brasil. \\ ${ }^{2}$ Corpo de Bombeiros Militar do Ceará, Fortaleza, CE, Brasil. \\ ${ }^{3}$ Agência Executiva de Gestão das Águas do Estado da Paraíba, Campina Grande, PB, Brasil.
}

Recebido em: 18 de Fevereiro de 2021 - Aceito em: 21 de Abril de 2021

\begin{abstract}
Resumo
O bioma Caatinga endêmico do Nordeste do Brasil, com uma dimensão de $844.453 \mathrm{~km}^{2}$, sofre anualmente com a incidência de incêndios, com prejuízos a fauna, flora e perdas econômicas e sociais e de infraestrutura física. Neste estudo investigou-se a relação de variáveis meteorológicas, tais como: velocidade do vento, temperatura, umidade do ar e outras observadas com focos de calor na área do bioma Caatinga. Tendo como base a série histórica de focos de calor 2002-2018, coletada do banco de dados do INPE. Analisou-se também as características mensais e sazonais de focos de calor no bioma Caatinga para a composição de anos de El Niño, La Niña e Neutros no Pacífico Tropical e com tipos de gradientes meridionais de temperatura da superfície do mar (TSMs) no Atlântico Tropical. Por metodologia quantitativa, calculou-se um índice de perigo de risco de focos de incêndio (IRFI) mensal. Através de análise dos dados e consecução por meio da metodologia proposta e possibilitar a obtenção dos resultados, identificou-se um perfil das características dos focos de calor registrados no bioma Caatinga em períodos mensais e sazonais (estações do ano) e suas variabilidades interanuais (2002-2018). Além disso, identificaram-se quais as variáveis meteorológicas na área do bioma que possuem mais relações com esses focos de calor observados.
\end{abstract}

Palavras-chaves: queimadas, variáveis meteorológicas, Caatinga.

\section{A Study of Heat Outputs in the Caatinga Biome and its Relationships with Meteorological Variables}

\begin{abstract}
The Caatinga biome endemic to the Northeast of Brazil, with a dimension of $844.453 \mathrm{~km}^{2}$, suffers annually with the incidence of fires, with damage to fauna, flora and economic and social losses and physical infrastructure. In this study, the relations of meteorological variables are investigated, such as: wind speed, temperature, air humidity and others as hot spots observed in the area Caatinga biome. Based on the 2002-2018 historical series, collected from the INPE database. The monthly and seasonal characteristics of hot spots in the Caatinga biome were analyzed for the composition of El Niño, La Niña and Neutral years in the Tropical Pacific and types of Sea Surface Temperatures (SSTs) Meridional Gradients in Tropical Atlantic and the relationships between these hot spots and meteorological variables. Using the quantitative methodology, a monthly fire hazard risk index (IRFI) was calculated. Through data analysis and achievement through the proposed methodology and enabling the achievement of results, a profile of the characteristics of the hot spots registered in the Caatinga biome in monthly and seasonal periods (seasons) and their interannual variability (2002-2018). In addition, it was identified the meteorological variables in the area of the biome that have more relationships with these observed hot spots.
\end{abstract}

Keywords: burned, meteorological variables, Caatinga.

Autor de correspondência: José Maria Brabo Alves. E-mail: jose.brabo@uece.br. 


\section{Introdução}

Um dos grandes problemas ambientais que o planeta enfrenta nos dias de hoje são os focos de incêndios. Seja por qualquer motivo essa ação destruidora tem impactos bastante fortes e duradouros no meio ambiente. Além do problema de destruir a vegetação com impactos ambientais imensuráveis, há que se ressaltar que o clima seco de várias regiões do Brasil em algumas épocas do ano, caso do bioma Caatinga, acaba tornando propício o alastramento do fogo. É necessário analisar e quantificar em que condições climáticas há mais ocorrências dessa natureza e com isso se possa prevenir possíveis desastres ambientais.

Conhecer as condições climáticas mais favoráveis para que ocorram focos de incêndios e saber preveni-los, é tão importante quanto saber apagá-los. Muitas vezes, um pequeno incêndio pode se tornar uma tragédia.

A história do incêndio data dos primórdios do desenvolvimento das sociedades e de seus espaços construídos. Sua evolução caminha ao lado do crescimento do poder econômico e, a cada descoberta tecnológica, está vinculado um fato histórico envolvendo o incêndio (Bonitese, 2007).

Um grande número de incêndios tem sido observado no Brasil e no mundo, com enormes dificuldades para seu controle, causando muitos prejuízos ao homem e, principalmente, ao meio ambiente, são os incêndios florestais.

As queimadas, utilizadas para limpar o terreno, vêm causando também perdas consideráveis na biodiversidade da Caatinga, com o desaparecimento de plantas e animais (Araújo Filho e Barbosa, 2000). Maciel (2010) ressalta que a Caatinga é o bioma mais ameaçado do Brasil, depois da Mata Atlântica e do Cerrado, e que as poucas áreas não alteradas formam arquipélagos.

As queimadas são recorrentes em todo o Brasil, de acordo com o Instituto Nacional de Pesquisas Espaciais INPE, dos 5075 focos de queimadas registrados em dezembro de 2018, o Bioma Caatinga concentrou 31\% desses focos, ficando em terceiro lugar de destaque nesses eventos de queimadas, perdendo apenas para os biomas Mata Atlântico e o Cerrado. Ressalta-se que o Ceará emplacou a marca de 723 focos de incêndios nesse mesmo mês do ano de 2018 (INPE, 2019).

Pelas afirmações anteriores, torna-se mais preocupante em saber que existem poucos trabalhos acadêmicos que abordam a temática, conforme observado numa pesquisa inicial em 2019, através do acesso ao banco de dados acadêmicos SciELO - Scientific Electronic Library Online.

A pergunta problema que surge ao fazer essa pesquisa é que: será que é possível, identificar quais as variáveis meteorológicas se correlacionam mais aos focos de calor e possíveis queimadas no Bioma Caatinga?

Almeida (2002) menciona que a relevância da temática reside no fato de que comprovadamente não existe no Brasil uma cultura voltada para a prevenção e preocupa- ção com os fatores de risco, especialmente os riscos de incêndio. Além de que, não se tem uma série histórica de dados suficiente desses focos de incêndios, pois, o monitoramento por satélites ambientais rotineiros é recente, com séries de dados a partir do início do final dos anos 90 .

Outra importância a se destacar está na colaboração para os órgãos de segurança ambiental e florestal, corpos de bombeiros e sociedade civil, dos estados incluídos no Bioma Caatinga, dentre eles o Ceará, que poderão se antecipar aos eventos danosos, criando alertas de forma preventivos para minimizar os efeitos das queimadas, traçando estratégias para melhorar a atuação preventiva nos meses mais quentes do ano.

A maioria dos países destina enormes montantes financeiros para protegerem-se do fogo em zonas especialmente sensíveis a ele como são as florestas (Deppe et al., 2004; Bowman et al., 2009; Granemann e Carneiro, 2009; Doerr e Santin, 2016). Estimativas mais conservadoras indicam custos médios anuais de US\$ $102 \mathrm{mi}-$ lhões ou $0,2 \%$ do PIB total da região da Amazônia para o período 1996-1999. Dependendo de como valoramos o carbono liberado, essas estimativas podem chegar a $9 \%$ do PIB regional. Esses valores já permitem mostrar que existe um amplo espaço de viabilidade de ações de prevenção e combate ao fogo na região (IPEA, 2002).

A justificativa do estudo está na necessidade de analisar algumas variáveis meteorológicas para a verificação da correlação com as queimadas no Bioma Caatinga. Identificar as variáveis meteorológicas que se correlacionam com esses incêndios é essencial tanto na prevenção, como também para rápida resposta dos órgãos competentes.

É possível que algumas variáveis meteorológicas facilitem o surgimento dos focos de incêndios nos biomas, sobretudo na Caatinga, região semiárida do nordeste brasileiro, que tem uma grande variabilidade interanual de precipitação e um longo período do ano seco.

Esse estudo tem como principal foco investigar as características dos focos de calor possíveis incêndiosqueimadas no bioma Caatinga e fazer uma correlação desses focos com algumas variáveis meteorológicas na região do bioma.

\section{Materiais e Métodos}

\subsection{Dados de focos de calor}

Os dados de focos de calor usados no estudo são do Instituto Nacional de Pesquisas Espaciais (INPE), disponíveis mensalmente para biomas brasileiros, estados em geral no período de 1998 até o presente. Para esse estudo os dados foram selecionados de 2002-2018. Os dados podem ser acessados no site do INPE, compilados diariamente sendo o número de focos de calor inferidos por satélites de órbita polar em uma dimensão espacial 
cobrindo o território brasileiro de $1 \mathrm{~km}^{2}$. A Fig. 1, embora os dados do estudo tenham sido usados entre 2002-2018, nessa figura é mostrado o número de focos de calor anuais para o estado do Ceará entre 1998-2019. Observa-se um aumento entre 2002-2008, e uma diminuição desses focos entre 2010-2019.

Segundo informações no site do INPE (2019) são utilizados todos os satélites que possuem sensores óticos operando na faixa termal-média de 4 microns, que o INPE consegue receber. Esses dados são processados operacionalmente, na Divisão de Satélites e Sistemas Ambientais DSA, e usam imagens do sensor AVHRR/3 dos satélites polares NOAA National Oceanic Atmospheric Admistration - 15, NOAA-18, NOAA-19 e METOP-B, as do MODIS, as dos NASA TERRA e AQUA, as do VIIRS do NPP-Suomi, e as imagens dos satélites geoestacionários, GOES-13 e MSG-3, estas imagens geram o número de focos de incêndios. Cada satélite de órbita polar produz pelo menos dois conjuntos de imagens por dia, e os geoestacionários geram várias imagens por hora, sendo que no total o INPE processa em torno de mais de 200 imagens por dia especificamente para detectar focos de queima da vegetação. Em 2017 foi incluída a recepção das imagens dos satélites chineses polares Fenyun e geoestacionário NOAA-GOES-16. As recepções são feitas nas estações de Cachoeira Paulista, SP e de Cuiabá, MT.

Um conceito de focos gerados pelo satélite de referência, que é o satélite cujos dados diários de focos detectados são usados para compor a série temporal ao longo dos anos e assim permitir a análise de tendências nos números de focos para mesmas regiões e entre regiões em períodos de interesse. De 01/junho/1998 a 03/julho/2002 foi utilizado o NOAA-12 (sensor AVHRR, passagem no final da tarde), e a partir de então o AQUA_M-T (sensor MODIS, passagem no início da tarde), segundo site do INPE (2019).

Quando o satélite AQUA deixar de operar, o satélite de referência passará a ser o NPP-SUOMI (Sensor VIIRS) da National Aeronautics and Space Administration -
NASA+NOAA_DoD dos Estados Unidos da América (EUA), lançado em outubro/2011, utilizado no monitoramento de focos pelo INPE desde 2012. A compatibilidade entre as séries será então ajustada cautelosamente, pois o VIIRS detecta até aproximadamente 10 vezes mais focos que o MODIS. Os dados dos satélites geoestacionários não são considerados como referência devido ao tamanho muito maior de seus píxeis e as instabilidades em sua rotina operacional (no caso GOES). Os dados de focos de referência divulgados pelo INPE coincidem com o conjunto de focos da NASA e da Universidade de Maryland (UMD) dos EUA denominada "Collection 5", que os produzem para todo o planeta.

\subsection{Dados meteorológicos}

Os dados meteorológicos usados para fazer inferências de relações com os focos de incêndios no bioma Caatinga foram coletados das reanálises do National Center for Environment Prediction - NCEP-NOAA (Kalnay et al. 1996). Esses dados têm resolução espacial de $2,5^{\circ}$ a $2,5^{\circ}$ de latitude e longitude e foram selecionados para uma área entre $80^{\circ} \mathrm{W}-10^{\circ} \mathrm{E}$ e $60^{\circ} \mathrm{S}-60^{\circ} \mathrm{N}$.

Valores mensais (2002-2018) das seguintes variáveis na atmosfera ou junto a superfície: precipitação, temperatura máxima do ar e temperatura do ar próxima a superfície, radiação incidente no solo, evapotranspiração, umidade relativa, conteúdo de umidade no solo e componentes zonais e meridionais do vento foram utilizados nesse estudo.

\section{Metodologia}

O método de tratamento e associação dos dados é apresentado pelas seguintes etapas:

1 - Cálculo de estatística básica, para mostrar as características mensais e sazonais (estações do ano, verão novembro a janeiro, outono - fevereiro a abril, inverno - maio a julho e primavera - agosto a outubro). Foram calculadas médias e desvios padrões para

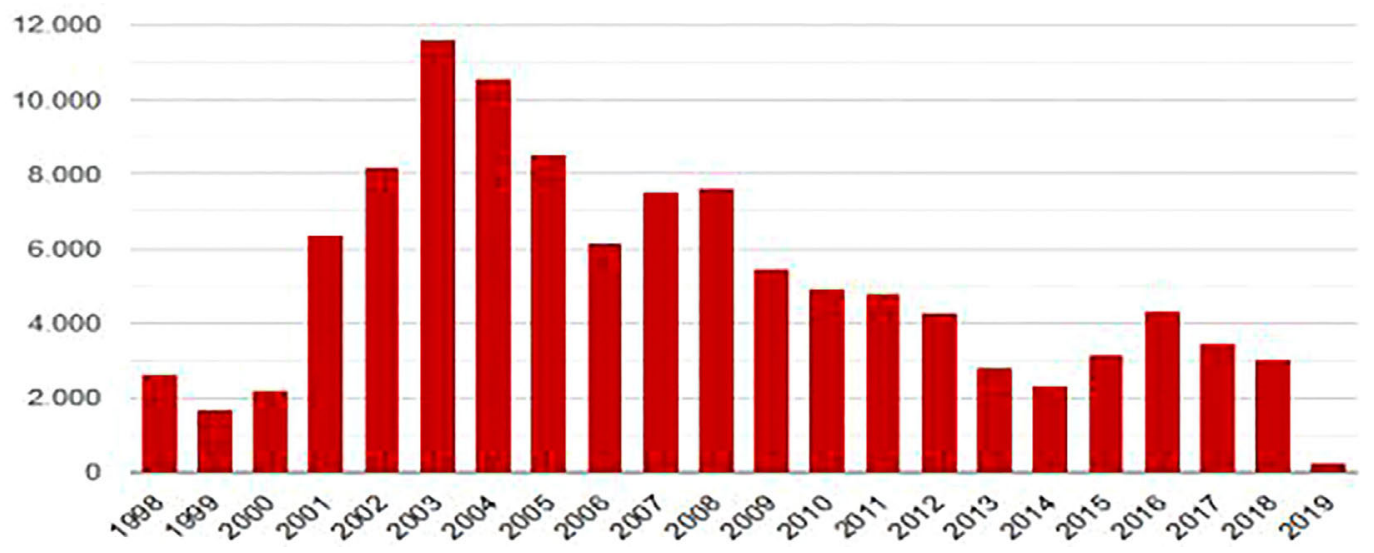

Figura 1 - Número de focos de calor-incêndios anuais no Estado do Ceará (1998-2019). Fonte: INPE (2019). 
os dados de focos de incêndios no bioma Caatinga, em uma área representativa da área do bioma $\left(2^{\circ} \mathrm{S}-\right.$ $18^{\circ} \mathrm{S}$ e $38^{\circ} \mathrm{W}-40^{\circ} \mathrm{W}$ ) e para as variáveis meteorológicas usadas nas correlações. Essas estatísticas foram calculadas para todos usando-se todos os meses do ano, individualmente, e respectivamente estes para as estações sazonais para os anos de contrastes climáticos definidos nas seções 4 e 5 .

2 - Correlações usando o coeficiente de correlação de Pearson mensal e sazonal entre o número de focos de incêndios no bioma Caatinga com os pontos de grade na área do bioma das variáveis meteorológicas. A significância estatística do coeficiente foi limitada a 95\% segundo o teste t Student.

3 - Correlações usando o coeficiente de correlação de Pearson mensal e sazonal entre o número de focos de incêndios no bioma Caatinga com o valor médio dos pontos de grade na área do bioma das variáveis meteorológicas. A significância estatística do coeficiente foi limitada a $95 \%$ segundo o teste t Student.

4 - Cálculo de anomalias mensais de focos de incêndios e índices de mecanismos físicos (fenômeno El NiñoOscilação Sul, dados pelas anomalias mensais na região Niño $3-4\left(5^{\circ} \mathrm{N}-5^{\circ} \mathrm{S}, 120^{\circ} \mathrm{W}-170^{\circ} \mathrm{W}\right)$ e do gradiente meridional de anomalias Temperatura da Superfície do Mar - TSMs no Atlântico Tropical (Gradat), é dado pela subtração das anomalias mensais nas suas áreas norte $\left(5,5^{\circ} \mathrm{N}-23,5^{\circ} \mathrm{N}, 15^{\circ} \mathrm{W}\right.$ $\left.57.5^{\circ} \mathrm{W}\right)$ menos sua área sul $\left(0^{\circ}-20^{\circ} \mathrm{S}-10^{\circ} \mathrm{E}-30^{\circ} \mathrm{W}\right)$. Esses dados foram coletados no site da NOAA, maiores detalhes dos mesmos são encontrados no site da esrl.NOAA. A significância estatística do coeficiente foi limitada a $95 \%$ segundo o teste t Student. Os meses de inferência de El Niño, La Niña e Neutros foram definidos quando as anomalias de TSMs na região de Niño $3-4$ esteve $>0,5{ }^{\circ} \mathrm{C},<-0,5{ }^{\circ} \mathrm{C}$ e $>=-0.5^{\circ} \mathrm{C}$ e $<=0.5{ }^{\circ} \mathrm{C}$, respectivamente. E para a definir os meses de Gradientes meridionais de anomalias de TSMs positivo, negativo e neutro quando a diferença entre a anomalia de TSM mensal da área norte do Atlântico menos a anomalias de TSM da sua área sul foi: $>0,2{ }^{\circ} \mathrm{C},<-0,2{ }^{\circ} \mathrm{C}$ e $>=-0.2{ }^{\circ} \mathrm{C}$ e $<=0.2{ }^{\circ} \mathrm{C}$, respectivamente. Todos os meses classificados nas categorias dos eventos definidos acima foram usados para suas estatísticas apresentados na seção de resultados e discussões.

5 - Cálculo de um índice de perigo de risco de focos de incêndio (IRFI) sazonal, estações do ano, inferido pelos dados de umidade relativa do ar e vento junto a superfície. Nesse estudo foi usado uma formulação aproximada de Monte Alegre (Machado et al. 2014), entre 2002-2018. O índice é dado pela fórmula $I R F I=\sum_{t=1}^{t=n} \frac{100}{U r_{t}} * 2,782^{0.04 v_{t}}$. Nessa fórmula, $n$ é o número de meses, na estação com chuva inferior a $5 \mathrm{~mm} /$ dia, $U_{r t}$ umidade relativa do ar (\%) e $v t$ é a velocidade do vento $(\mathrm{m} / \mathrm{s})$ De acordo com Machado et al. 2014 o risco de incêndio inferido por esse índice é indicado por meio de uma escala de cinco níveis, de acordo com o seu valor que varia entre: Nulo (0-3); Pequeno (3,1-8); Médio (8,1-14); alto (14,1-24); e Muito Alto (>24). Um IRFI médio foi calculado para as estações do ano entre 2002-2018.

\section{Análises e Discussão}

\subsection{Estatísticas sobre os focos de calor no Bioma Caatinga}

Nessa seção se faz uma análise climatológica (20022018) das principais medidas de tendência central explicitas pela média e de dispersão pelo desvio padrão e coeficiente de variação para os focos de incêndio no bioma Caatinga e comparam-se as mesmas com anos de contrastes climáticos de ocorrência de El Niño, La Niña, Neutros e de categorias do Gmat.

A Tabela 1 mostra a estatística do número de focos de calor para a composição de anos de La Niñas e para o período entre 2002-2018. DP significa desvio padrão, Dif

Tabela 1 - Médias, desvios padrões e desvios absolutos (Dif) e significância segundo teste $\mathrm{t}$ Student do número de focos de calor para a composição de anos de La Niñas comparado ao período entre 2002-2018.

\begin{tabular}{lcccccc}
\hline Mês & $\begin{array}{c}\text { Médias } \\
\text { La Niñas }\end{array}$ & $\begin{array}{c}\text { Médias } \\
(2002-2018)\end{array}$ & $\begin{array}{c}\text { DP La } \\
\text { Ninãs }\end{array}$ & $\begin{array}{c}\text { Dp } \\
(2002-2018)\end{array}$ & Dif & Sig \\
\hline JAN & 707,67 & 619,35 & 344,04 & 2,06 & $-88,31$ & 95 \\
FEV & 190,17 & 175,12 & 96,22 & 1,98 & $-15,05$ & 95 \\
MAR & 150,5 & 156,29 & 61,11 & 2,46 & 5,79 & 5 \\
ABR & 105,5 & 97,47 & 13,22 & 7,98 & $-8,03$ & 95 \\
MAI & 54,0 & 91,76 & 37,76 & 1,43 & 37,76 & 5 \\
JUN & 114,5 & 142,76 & 58,75 & 1,95 & 28,26 & 5 \\
JUL & 438,67 & 342,53 & 260,78 & 1,68 & $-96,14$ & 95 \\
AGO & 1537,75 & 1073,06 & 627,22 & 2,45 & $-464,69$ & 95 \\
SET & 3799,0 & 3588,18 & 1181,73 & 3,21 & $-210,82$ & 95 \\
OUT & 5227,4 & 5123,06 & 1821,51 & 2,87 & $-104,34$ & 95 \\
NOV & 5176,57 & 4639,82 & 2120,19 & 2,44 & $-536,75$ & 95 \\
DEZ & 3177,29 & 3239,24 & 1436,34 & 2,21 & 61,95 & 5 \\
\hline
\end{tabular}

Nota-se que em alguns meses que climatologicamente são mais chuvosos no bioma Caatinga (primeiros seis meses do ano), a média dos focos desses anos é um pouco menor do que a média para 2002-2018, refletindo a influência da precipitação na situação de focos de incêndios. Essa característica não é observada no segundo semestre do ano, em que a média de focos é maior para composição de anos de La Niña do que para o período base 2002-2018. Esse fato pode estar associado às queimadas feitas para o cultivo agrícola e preparação do solo no segundo semestre de um ano que foi em geral chuvoso, que ainda nesse período mantém umidade no solo favorável ao cultivo. Os desvios padrões em todos os meses são bem maiores nos anos de La Niñas, e quase inexpressivos entre 2002-2018. Para todos os meses as diferenças nesses anos de La Niñas há uma variabilidade de diferenças significativas a $95 \%$ e $5 \%$. 
é a diferença entre a média entre 2002-2018 menos a média para a composição dos anos de La Niña. Sig é a significância estatística das diferenças.

A Tabela 2 mostra a estatística do número de focos de calor para a composição de anos de El Niños e para o período entre 2002-2018. DP significa desvio padrão, Dif é a diferença entre a média entre 2002-2018 menos a média para a composição dos anos de El Niño. Sig é a significância estatística das diferenças. Pode-se observar que nos meses de janeiro e junho a média dos focos de calor foram um pouco maiores que o período base de estudo (2002-2018).

No segundo semestre essas médias de focos diminuíram em relação à média do período base, porém aumentaram em números em relação ao primeiro semestre, chegando a mais de 4000 focos em outubro e novembro. A variabilidade mensal nessa composição de anos de El Niños também como nos anos de La Niñas é muita alta como mostra os valores de desvios padrões para os doze meses do ano. Ressalta-se a significância estatística de 95\% nessas diferenças mensais para essa composição de anos de El Niños nos meses de janeiro, junho, julho, setembro e dezembro.

A Tabela 3 mostra a estatística do número de focos de calor para a composição de anos de Neutros e para o período entre 2002-2018. DP significa desvio padrão, Dif é a diferença entre a média entre 2002-2018 menos a média para a composição dos anos Neutros. Sig é a significância estatística das diferenças.

Observa-se por essa Tabela 3 que para esses anos Neutros houve certa similaridade a observada nos anos de El Niños, também nos primeiros seis meses do ano a média dos focos de calor em alguns meses foram um pouco maiores que o período base de estudo (2002-2018).

Para o segundo semestre, como nos anos de Niños, essas médias de focos diminuíram em relação à média do período base, porém aumentaram em números em relação

Tabela 2 - Como a Tabela 1 para a composição dos anos de El Niños.

\begin{tabular}{lcccccc}
\hline Mês & $\begin{array}{c}\text { Médias } \\
\text { El Niños }\end{array}$ & $\begin{array}{c}\text { Médias } \\
(2002-2018)\end{array}$ & $\begin{array}{c}\text { DP El } \\
\text { Niños }\end{array}$ & $\begin{array}{c}\text { Dp } \\
(2002-2018)\end{array}$ & Dif & Sig \\
\hline JAN & 718,86 & 619,35 & 393,4 & 1,83 & $-99,5$ & 95 \\
FEV & 172,5 & 175,12 & 89,62 & 1,92 & 2,62 & 5 \\
MAR & 126,25 & 156,29 & 101,76 & 1,24 & 30,04 & 5 \\
ABR & 69,67 & 97,47 & 40,68 & 1,71 & 27,8 & 5 \\
MAI & 74,5 & 91,76 & 18,45 & 4,04 & 17,26 & 5 \\
JUN & 164,75 & 142,76 & 35,06 & 4,7 & $-21,99$ & 95 \\
JUL & 365,5 & 342,53 & 134,33 & 2,72 & $-22,97$ & 95 \\
AGO & 1016,83 & 1073,06 & 389,26 & 2,61 & 56,23 & 5 \\
SET & 3846,33 & 3588,18 & 950,48 & 4,05 & $-258,16$ & 95 \\
OUT & 4623,71 & 5123,06 & 2075,01 & 2,23 & 499,34 & 5 \\
NOV & 4313,63 & 4639,82 & 2011,17 & 2,14 & 326,2 & 5 \\
DEZ & 3449 & 3239,24 & 1901,8 & 1,81 & $-209,76$ & 95 \\
\hline
\end{tabular}

Tabela 3 - Como a Tabela 1 para a composição de anos de Neutros.

\begin{tabular}{lcccccc}
\hline Mês & $\begin{array}{c}\text { Médias } \\
\text { Neutros }\end{array}$ & $\begin{array}{c}\text { Médias } \\
(2002-2018)\end{array}$ & $\begin{array}{c}\text { DP } \\
\text { Neutros }\end{array}$ & $\begin{array}{c}\text { Dp } \\
(2002-2018)\end{array}$ & Dif & Sig \\
\hline JAN & 312 & 619,35 & 326,4 & 0,96 & 307,35 & 5 \\
FEV & 138,5 & 175,12 & 80,53 & 1,72 & 36,62 & 5 \\
MAR & 161,64 & 156,29 & 89,48 & 1,81 & $-5,34$ & 95 \\
ABR & 98,64 & 97,47 & 59,4 & 1,66 & $-1,17$ & 95 \\
MAI & 95 & 91,76 & 63,6 & 1,49 & $-3,24$ & 95 \\
JUN & 147,54 & 142,76 & 88,22 & 1,67 & $-4,77$ & 95 \\
JUL & 312,54 & 342,53 & 182,14 & 1,72 & 29,99 & 5 \\
AGO & 929,78 & 1073,06 & 459,84 & 2,02 & 143,28 & 5 \\
SET & 3225,67 & 3588,18 & 1576,47 & 2,05 & 362,51 & 5 \\
OUT & 5158,29 & 5123,06 & 2426,73 & 2,13 & $-35,23$ & 95 \\
NOV & 3548,75 & 4639,82 & 3034,89 & 1,17 & 1091,07 & 5 \\
DEZ & 2573,5 & 3239,24 & 1707,35 & 1,51 & 665,74 & 5 \\
\hline
\end{tabular}

ao primeiro semestre, chegando a mais de 5000 focos em outubro.

A variabilidade mensal nessa composição de anos de Neutros também como nos anos de La Niñas e Niños foi alta como mostra os valores de desvios padrões para os doze meses do ano. Ressalta-se também a significância estatística de $95 \%$ das médias mensais para essa composição de anos de Neutros de abril a junho e outubro.

A Tabela 4 mostra a estatística do número de focos de calor para a composição de anos de DIPNEG e para o período entre 2002-2018. DP significa desvio padrão, Dif é a diferença entre a média entre 2002-2018 menos a média para a composição dos anos de DIPNEG. Sig é a significância estatística das diferenças.

Observa-se que para esses anos de DIPNEG houve semelhança a observada nos anos de La Niñas. Nota-se que nos meses que climatologicamente é mais chuvoso no bioma Caatinga também em alguns meses, a média dos focos desses anos é um pouco menor do que a média para

Tabela 4 - Como a Tabela 1 para a composição de anos de DIPNEG.

\begin{tabular}{lcccccc}
\hline Mês & $\begin{array}{c}\text { Médias } \\
\text { DipNeg }\end{array}$ & $\begin{array}{c}\text { Médias } \\
(2002-2018)\end{array}$ & $\begin{array}{c}\text { DP } \\
\text { DipNeg }\end{array}$ & $\begin{array}{c}\text { Dp } \\
(2002-2018)\end{array}$ & Dif & Sig \\
\hline JAN & 615,86 & 619,35 & 346,38 & 1,78 & 3,5 & 5 \\
FEV & 182,6 & 175,12 & 88,43 & 2,06 & $-7,48$ & 95 \\
MAR & 144,75 & 156,29 & 53,17 & 2,72 & 11,54 & 5 \\
ABR & 92,29 & 97,47 & 47,99 & 1,92 & 5,18 & 5 \\
MAI & 71,14 & 91,76 & 41,86 & 1,7 & 20,62 & 5 \\
JUN & 147,75 & 142,76 & 64,5 & 2,29 & $-4,99$ & 95 \\
JUL & 385,0 & 342,53 & 200,88 & 1,92 & $-42,47$ & 95 \\
AGO & 1516,0 & 1073,06 & 442,94 & 3,42 & $-442,94$ & 95 \\
SET & 3711,4 & 3588,18 & 1552,96 & 2,39 & $-123,22$ & 95 \\
OUT & 2476,0 & 5123,06 & 2647,06 & 0,94 & 2647,06 & 5 \\
NOV & 1876,0 & 4639,82 & 2763,82 & 0,68 & 2763,82 & 5 \\
DEZ & 1720,0 & 3239,24 & 1559,26 & 1,1 & 1519,24 & 5 \\
\hline
\end{tabular}


2002-2018, refletindo a influência da precipitação na situação de ocorrência de focos de calor.

Essa característica não é observada no segundo semestre do ano, em que a média de focos é maior para composição de anos de DIPNEG do que para o período base 2002-2018. Esse fato pode estar associado, como nos anos de La Niñas, às queimadas feitas para o cultivo agrícola e preparação do solo no segundo semestre de uma no que foi em geral chuvoso, que ainda nesse período mantém umidade no solo favorável ao cultivo. Os desvios padrões em todos os meses são bem maiores nos anos de DIPNEG, e quase inexpressivos entre 2002-2018. Para todos os meses as diferenças nesses anos de DIPNEG na foram significativas a $95 \%$, entre junho a setembro e em fevereiro.

A Tabela 5 mostra a estatística do número de focos de calor para a composição de anos de DIPNEU e para o período entre 2002-2018. DP significa desvio padrão, Dif é a diferença entre a média entre 2002-2018 menos a média para a composição dos anos de DIPNEU. Sig é a significância estatística das diferenças.

Pode-se observar que diferente dos anos de DIPNEU, nos primeiros seis meses do ano a média dos focos de calor apresentou valores maiores na maioria dos meses do que o período base de estudo (2002-2018).

Para o segundo semestre essas médias de focos também foram muito variáveis alternando valores acima e abaixo da média do período base, porém também aumentaram em números em relação ao primeiro semestre, chegando a mais de 5000 focos a partir de novembro. A variabilidade mensal nessa composição de anos de DIPNEU também como nos anos de DIPNEG é muita alta como mostra os valores de desvios padrões para os doze meses do ano. Ressalta-se a significância estatística de 95\%das diferenças mensais para essa composição de anos de DIPNEU de março a maio, em setembro e para novembro e dezembro.

Tabela 5 - Como a Tabela 1 para a composição de anos de DIPNEU.

\begin{tabular}{lcccccc}
\hline Mês & $\begin{array}{c}\text { Médias } \\
\text { DipNeu }\end{array}$ & $\begin{array}{c}\text { Médias } \\
(2002-2018)\end{array}$ & $\begin{array}{c}\text { DP } \\
\text { DipNeu }\end{array}$ & $\begin{array}{c}\text { Dp } \\
(2002-2018)\end{array}$ & Dif & Sig \\
\hline JAN & 612,43 & 619,35 & 333,23 & 1,84 & 6,92 & 5 \\
FEV & 173,88 & 175,12 & 95,32 & 1,82 & 1,24 & 5 \\
MAR & 163,4 & 156,29 & 125,62 & 1,3 & $-7,11$ & 95 \\
ABR & 109,88 & 97,47 & 62,8 & 1,75 & $-12,4$ & 95 \\
MAI & 101,25 & 91,76 & 76,22 & 1,33 & $-9,49$ & 95 \\
JUN & 85,2 & 142,76 & 63,75 & 1,34 & 57,56 & 5 \\
JUL & 289,44 & 342,53 & 185,62 & 1,56 & 53,08 & 5 \\
AGO & 964 & 1073,06 & 466,8 & 2,07 & 109,06 & 5 \\
SET & 4102,71 & 3588,18 & 1766,32 & 2,32 & $-514,54$ & 95 \\
OUT & 4568,29 & 5123,06 & 2013,61 & 2,27 & 554,77 & 5 \\
NOV & 5411,17 & 4639,82 & 2394,87 & 2,26 & $-771,34$ & 95 \\
DEZ & 4089,7 & 3239,24 & 1865,95 & 2,19 & $-850,46$ & 95 \\
\hline
\end{tabular}

Para a composição de anos de DIPPOS a estatística da média do número de focos mensal, seus desvios padrões, diferença entre suas médias e as médias para o período 2002-2018 é apresentada na Tabela 6. Uma característica marcante é uma maior variabilidade no número de focos ao longo do ano composição dos anos de DIPPOS, alternando valores maiores e menores do que aos observados no período base de 2002-2018. Isto indica que anos com irregularidade de chuvas, quando as condições térmicas do Oceano Atlântico Tropical têm um gradiente térmico da sua bacia sul para sua bacia norte (Rodrigues et al., 2014; Nobre e Shukla, 1996, Uvo et al., 1998), os incêndios são variáveis em quase todo o ano. Essa característica foi observada também em alguns dos últimos seis meses as categorias de DIPNEU.

Como para as outras composições de anos os desvios padrões têm valores muito altos quando comparados aos do período 2002-2018, com os maiores desvios predominantemente nos meses de outubro, novembro e dezembro, e os menores nos meses do período mais chuvoso no bioma Caatinga, fevereiro a junho. Quanto à significância das diferenças para composição desses anos de DIPPOS a mesma foi significativa a $95 \%$ segundo o teste $t$ Student nos meses de março, junho, julho, agosto e outubro.

\subsection{Variabilidade interanual dos focos de calor no Bioma Caatinga e suas relações com variáveis atmosféricas}

Essa seção faz-se uma análise das ocorrências de focos de calor no bioma Caatinga e suas variabilidades interanuais (2002-2018), e relaciona essa variabilidade com algumas características das variáveis atmosféricas e de superfície estudadas.

A Fig. 2 mostra a variabilidade mensal interanual dos focos de calor ocorridos na Caatinga. Nota-se por essa figura que os meses de setembro a dezembro, em geral

Tabela 6 - Como a Tabela 1 para a composição de anos de DIPPOS.

\begin{tabular}{lcccccc}
\hline Mês & $\begin{array}{c}\text { Médias } \\
\text { DipPos }\end{array}$ & $\begin{array}{c}\text { Médias } \\
(2002-2018)\end{array}$ & $\begin{array}{c}\text { DP } \\
\text { DipPos }\end{array}$ & $\begin{array}{c}\text { Dp } \\
(2002-2018)\end{array}$ & Dif & Sig \\
\hline JAN & 570,83 & 619,35 & 382,95 & 1,49 & 48,52 & 5 \\
FEV & 167,57 & 175,12 & 91,06 & 1,84 & 7,55 & 5 \\
MAR & 170,40 & 156,29 & 81,54 & 2,09 & $-14,11$ & 95 \\
ABR & 74,20 & 97,47 & 37,56 & 1,98 & 23,27 & 5 \\
MAI & 85,67 & 91,76 & 32,85 & 2,61 & 6,10 & 5 \\
JUN & 165,14 & 142,76 & 98,80 & 1,67 & $-22,38$ & 95 \\
JUL & 385,14 & 342,53 & 183,59 & 2,10 & $-42,61$ & 95 \\
AGO & 1183,00 & 1073,06 & 501,32 & 2,36 & $-109,94$ & 95 \\
SET & 3228,00 & 3588,18 & 1045,65 & 3,09 & 360,18 & 5 \\
OUT & 5439,92 & 5123,06 & 2197,04 & 2,48 & $-316,86$ & 95 \\
NOV & 4462,00 & 4639,82 & 2242,17 & 1,99 & 177,82 & 5 \\
DEZ & 2575,00 & 3239,24 & 1615,78 & 1,59 & 664,24 & 5 \\
\hline
\end{tabular}




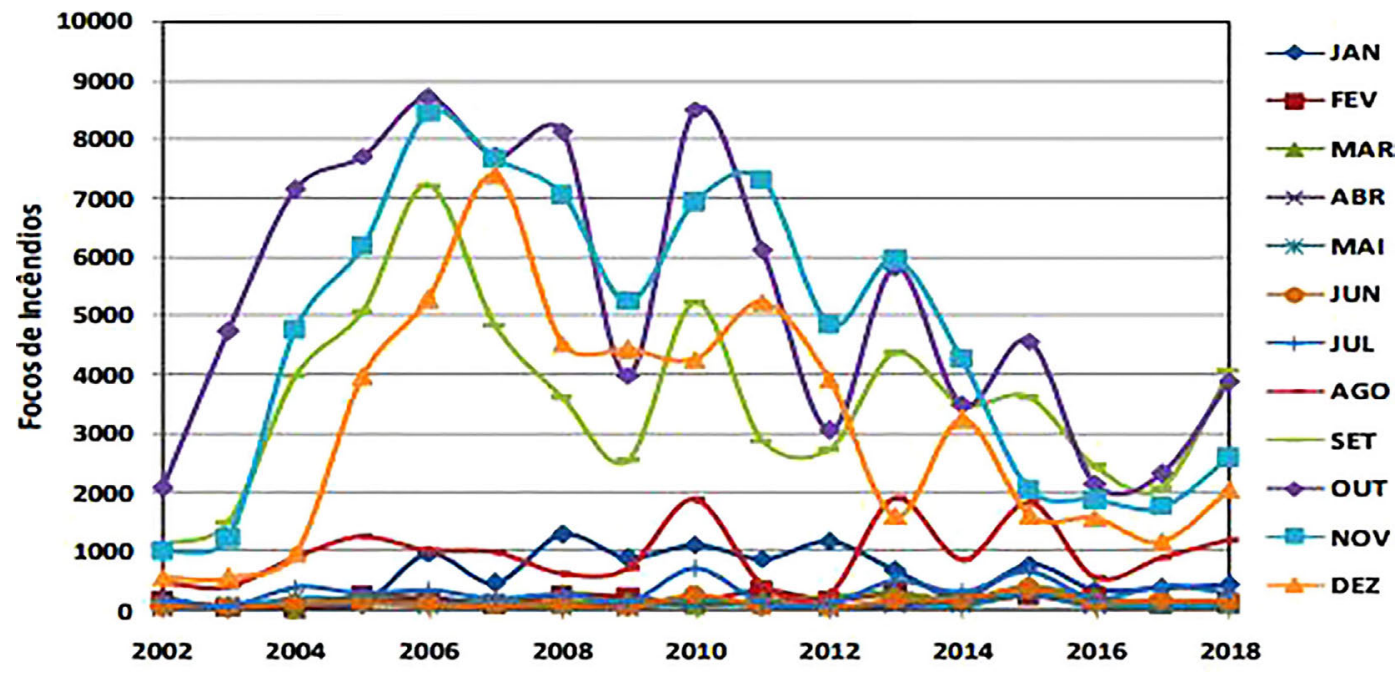

Figura 2 - Número de focos de calor anuais no Bioma Caatinga (2002-2018).

mais secos na região, apresentam números mais altos de focos de calor, em geral acima de 4000 focos por mês, principalmente até os anos 2010.

Essa característica coincide com os meses em que os ventos nessa região são mais fortes (superiores a $4 \mathrm{~m} / \mathrm{s}$ dados de reanálise). A partir 2010 ocorreu um declínio nesses focos de calor o que deve estar associado a uma melhor prática de monitoramento e de combate a esses focos pelo governo federal e estadual.

As análises a seguir relacionam características físicas das variáveis atmosféricas e de superfície e se estas estão relacionadas a possíveis mais focos de calor. Inferese o percentual de meses, por exemplo, para janeiro de 2002-2018, e se essas características se associaram a desvios positivos no número de focos de calor no bioma Caatinga. Isto é, para temperaturas do ar e no solo, se em um dado mês o seu desvio foi positivo e coincidiu com desvio positivo de focos, esse percentual foi contado. Assim para as demais variáveis com as seguintes características associadas a desvios positivos de focos: precipitação, evapotranspiração e umidade no solo (desvios negativos), radiação incidente no solo (desvios positivos) e ventos (desvios positivos). Nesse caso dos ventos desvios positivos inferem a possibilidade e uma maior propagação de focos de calor.

As Figs. 3a a 3h mostram a relação mencionada acima entre as variáveis e o número de focos de calor dados pelos percentuais de meses em cada ano com condições físicas favoráveis aos focos.

Nota-se por todas as figuras que não há percentuais expressivos acima de $50 \%$ entre as condições das variáveis favoráveis aos focos de queimadas em todas as variáveis e para todos os meses do ano. Para a Temperatura do ar (Fig. 3a) os maiores percentuais em torno de $30 \%$ foram

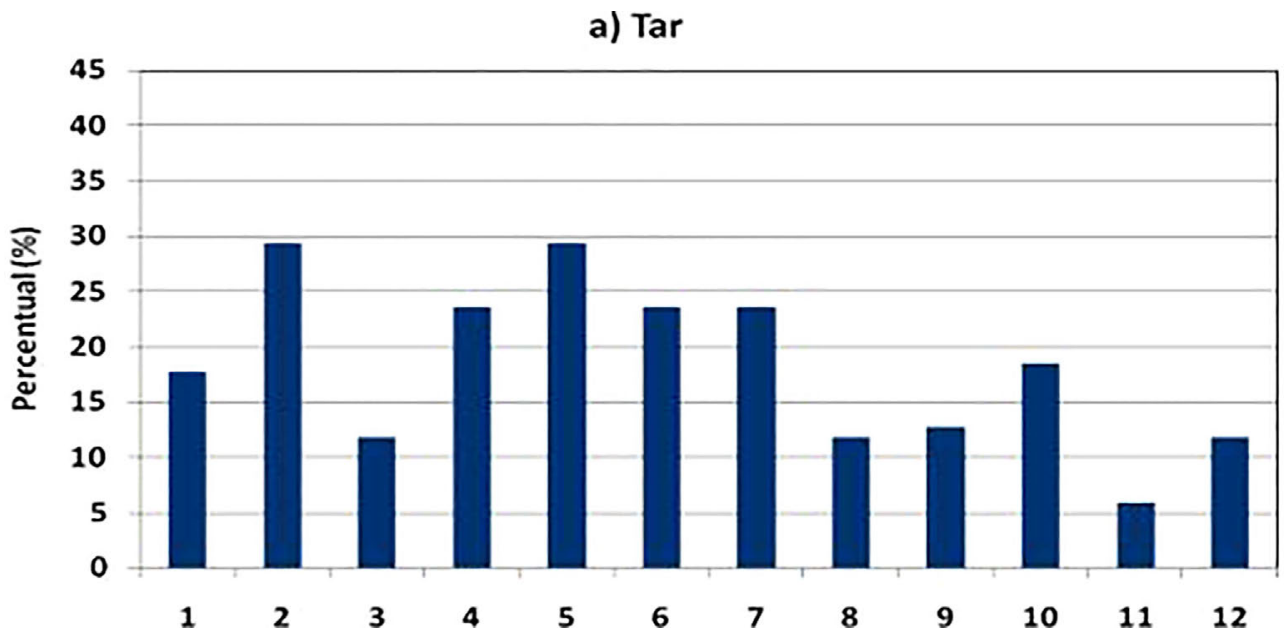

Figura 3a - Percentual Mensais de Condições Favoráveis (anomalia de Tar positiva) entre 2002-2018 para ocorrência de focos de calor no bioma Caatinga. 
observados nos meses de fevereiro e maio, menores percentuais em torno e abaixo de $10 \%$ foram observados nos meses de março, agosto e setembro e em novembro e dezembro.

Para a variavel precipitação esses percentuais são mostrados na Fig. 3b. Os maiores acima de 35\% aproximandamente entre os meses de fevereiro a junho, coincidente com o período chuvoso em grande parte do bioma Caatinga. Esses percentuais maiores inferem que nesses meses precipitação média no bioma abaixo da média esteve associada a anomalias de focos de incendios acima da média. Como no segundo semestre do ano em geral já é mais seco climatologicamente no bioma, essa relação entre esses valores de percentuais e a anomalia positiva de focos de incêncios não foi expressva.
A Fig. 3c mostra esses percentuais mensais para a variável evatranspiração potencial. Pode-se obervar que maiores percentuais predominam entre os meses de agosto a dezembro, em geral, período de um maior número de focos de calor durante os anos no bioma Caatinga. Isso sugere que mesmo nesse período mais seco, já favorável a ocorrência de incêndios, se houver meses com mais evapotranspiração que a média, o solo do bioma tenderá a fica mais seco e mais vulnerável a focos de incêndios.

A Fig. 3d apresenta os percentuais mensais (entre 2002-2018) para a variável vento em superfície. Nota-se nsta figura uma característica semelhante a variável precipotação, percentuais acima de $35 \%$ entre fevereiro a junho. Implicando que anomalias de ventos em média no

b) Prp

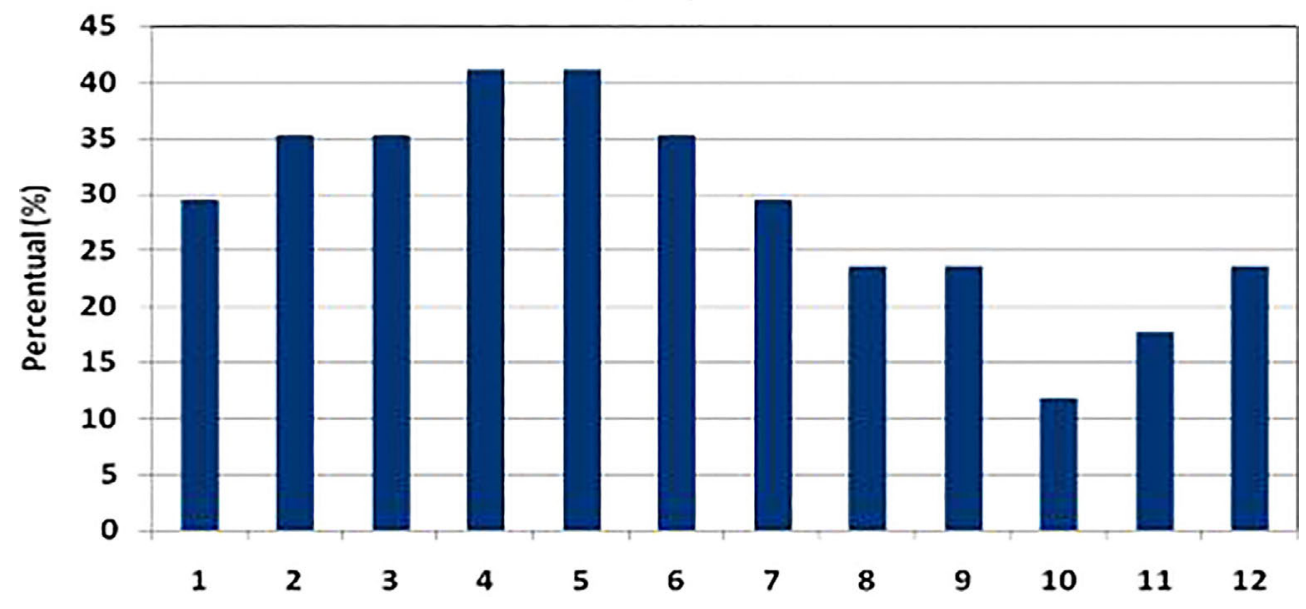

Figura 3b - Percentual Mensais de Condições Favoráveis (anomalia de precipitação negativa) entre 2002-2018.

\section{c) Etp}

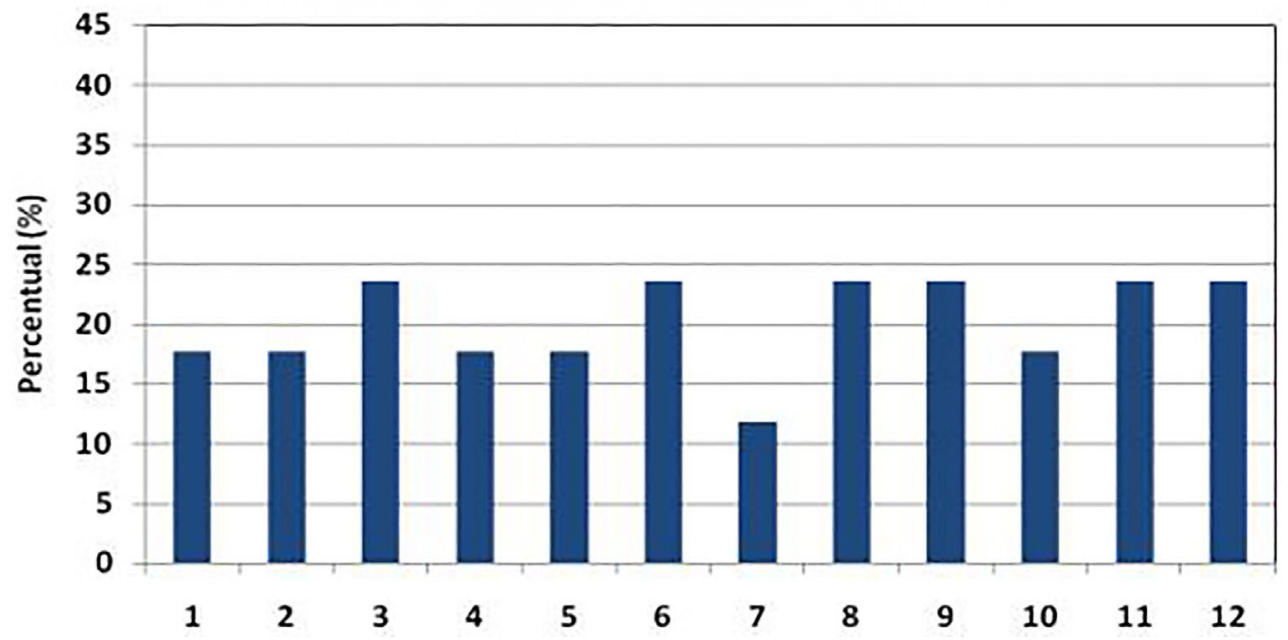

Figura 3c - Percentual mensais de condições favoráveis (anomalia de evapotranspiração positiva) entre 2002-2018 para ocorrência de focos de calor anuais no bioma Caatinga. 
d) Vento Sup.

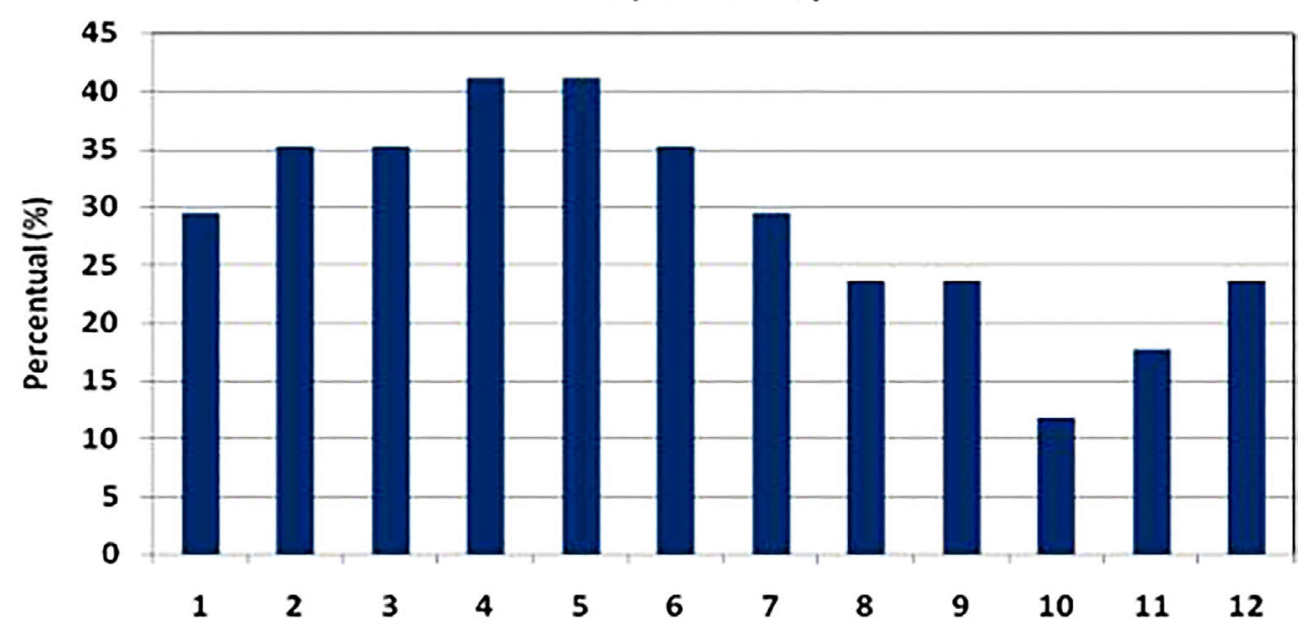

Figura 3d - Percentual mensais de condições favoráveis (anomalia de ventos em superfície positiva) entre 2002-2018 para ocorrência de focos de calor anuais no bioma Caatinga.

bioma positivas nesse período de chuvas pode favorecer a focos de calor.

Para a umidade relativa do ar esses percentuais mensais (2002-2018) que fisicamente são favoráveis a focos de calor são mostrados na Fig. 3e Mais uma vez pecentuais mais expressivos em valores apareceram com predomínio nos meses da estação chuvosa no bioma Caatinga, entre janeiro a junho, Isso indica que umidade relativa com valores abaixo da média, em geral, associaram-se com focos de calor com valores acima da média.

A Fig. 3f mostra os percentuais de condições favoráveis mensais (2002-2018) para ocorrência de focos de calor, ou seja anomalias de radiação positiva coincidindo com anomalias positivas de mensais de focos de calor. Os maiores percentuais com valores acima de $30 \%$ foi observado no mes de setembro. No restante dos meses do ano os percentuias são menores, principalmente nos meses de abril e junho, valores inferiores a $30 \%$.

Para temperatura do solo esses percentuais mensais (2002-2018) que fisicamente são favoráveis a focos de calor são mostrados na Fig. 3g. Mais uma vez pecentuais mais expressivos em valores apareceram com predomínio nos meses de setembto e dezembro, meses mais quentes no bioma Caatinga. Além desses meses também entre os meses de fevereiro a março, os percentuais foram acima de $20 \%$. Nos meses mais quentes de setembro a dezembro, essa característica dos percentusis inferem que anomalias positivas de tempertura do solo associaram-se a

e) Ur

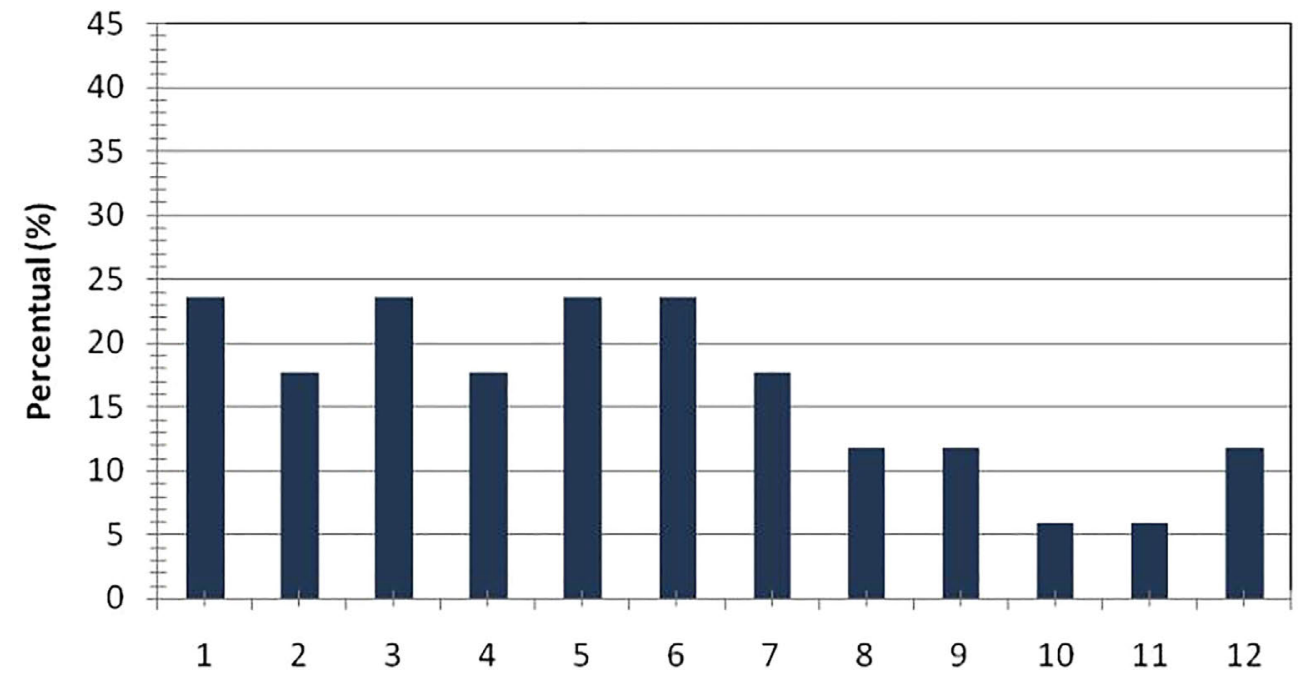

Figura 3e - Percentual mensais de condições favoráveis (anomalia de umidade relativa do ar negativa) entre 2002-2018 para ocorrência de focos de calor anuais no bioma Caatinga. 


\section{f) Radiação a Sup.}

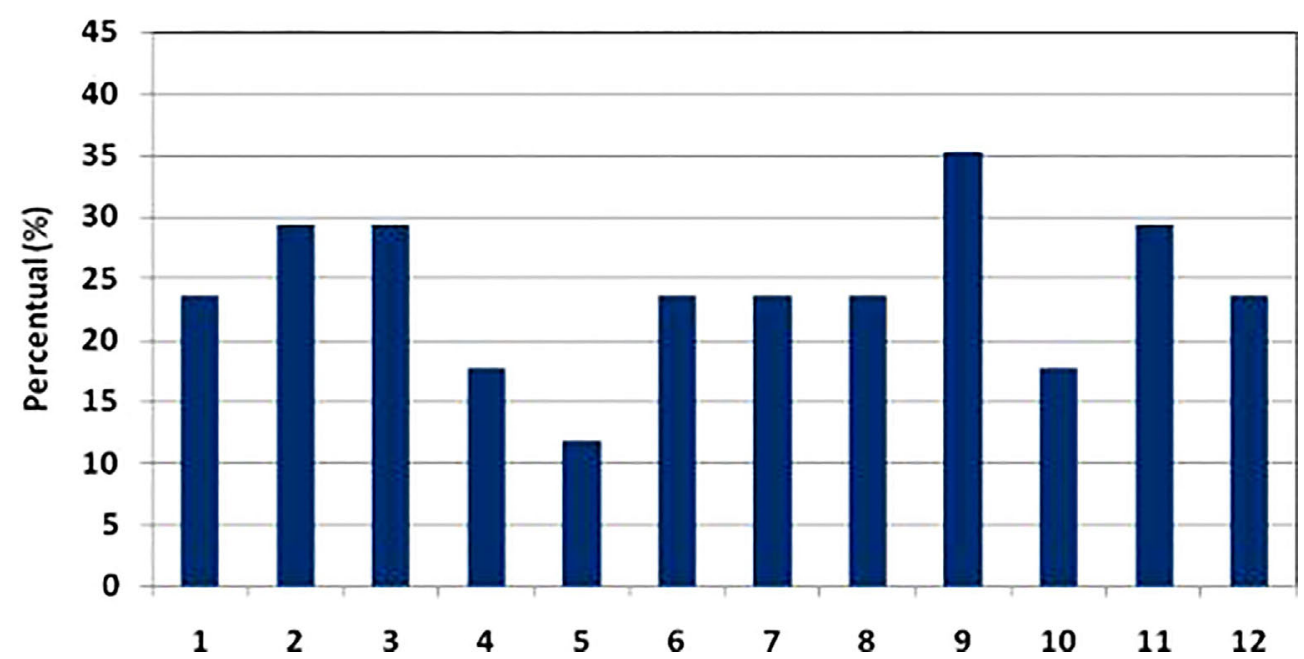

Figura 3f - Percentual mensais de condições favoráveis (anomalia radiação em superfície positiva) entre 2002-2018 para ocorrência de focos de calor anuais no bioma Caatinga.

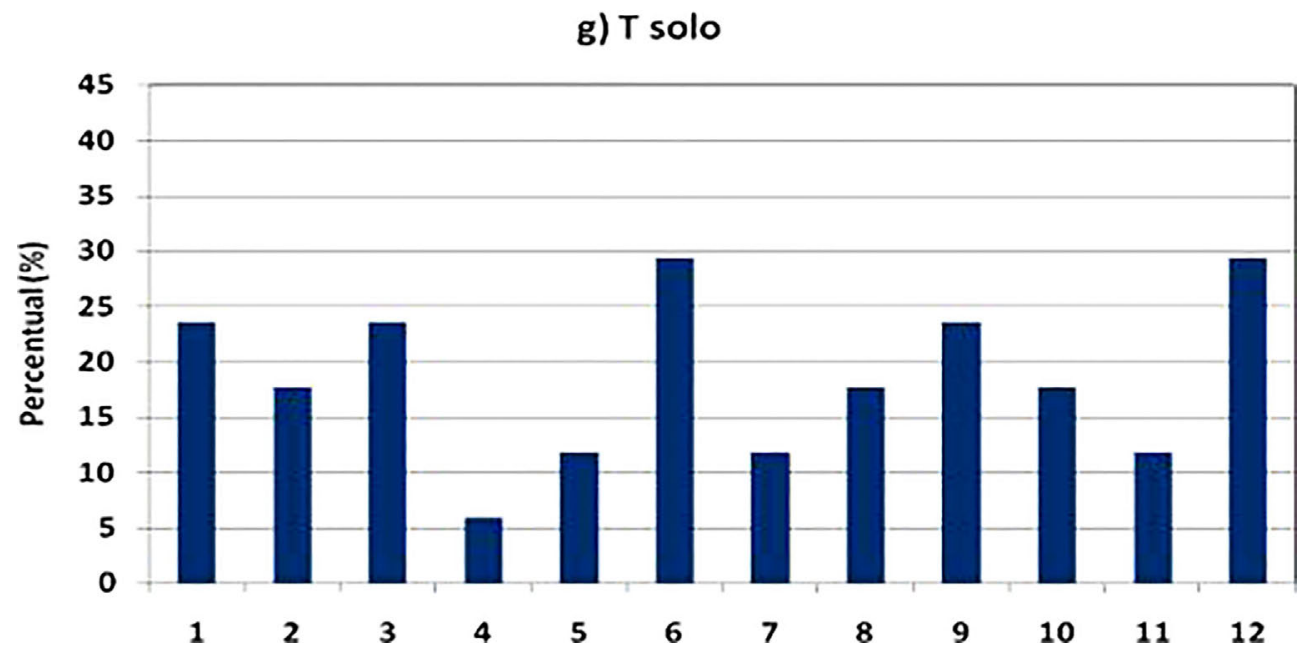

Figura 3g - Percentual mensais de condições favoráveis (anomalia temperatura do solo positiva) entre 2002-2018 para ocorrência de focos de calor anuais no bioma Caatinga.

anomalias positivas de focos de calor com valores acima da média.

Na Fig. 3h são mostrados os percentuais mensais (2002-2018) das características favoráveis a ocorreência de focos de calor acima da média. Os valores em geral são inferiores a $20 \%$, exceto nos meses de março, junho e agosto cujos valores foram superiores a $20 \%$.

\subsection{Correlações entre focos de calor e variáveis atmosféricas e de superfície}

Nessa seção faz-se uma análise da correlação entre os focos de calor no bioma Caatinga com as variáveis meteorológicas e de superfície com duas formas de análise. Uma análise é uma correlação espacial sobre a área do bioma Caatinga, usando esses totais dos focos de calor no bioma com esses totais das estações das variáveis usadas em pontos de grade da área do bioma. Na correlação espacial é mostrada essa relação em duas estações que chovem mais (verão e outono) e menos (inverno e primavera) no bioma Caatinga. São mostradas apenas as variáveis que na área do bioma Caatinga a correlação apresentou áreas significativas a 95\% segundo teste $\mathrm{t}$ Student.

Para outra análise foram calculados os coeficientes mensais (todos os meses de janeiro e dezembro) e sazonais (estações do ano). Esse cálculo levou em conta os valores dos totais mensais e das estações dos focos de calor no bioma Caatinga com um valor médio das variáveis meteorológicas calculados na área repre- 


\section{h) Umidade solo}

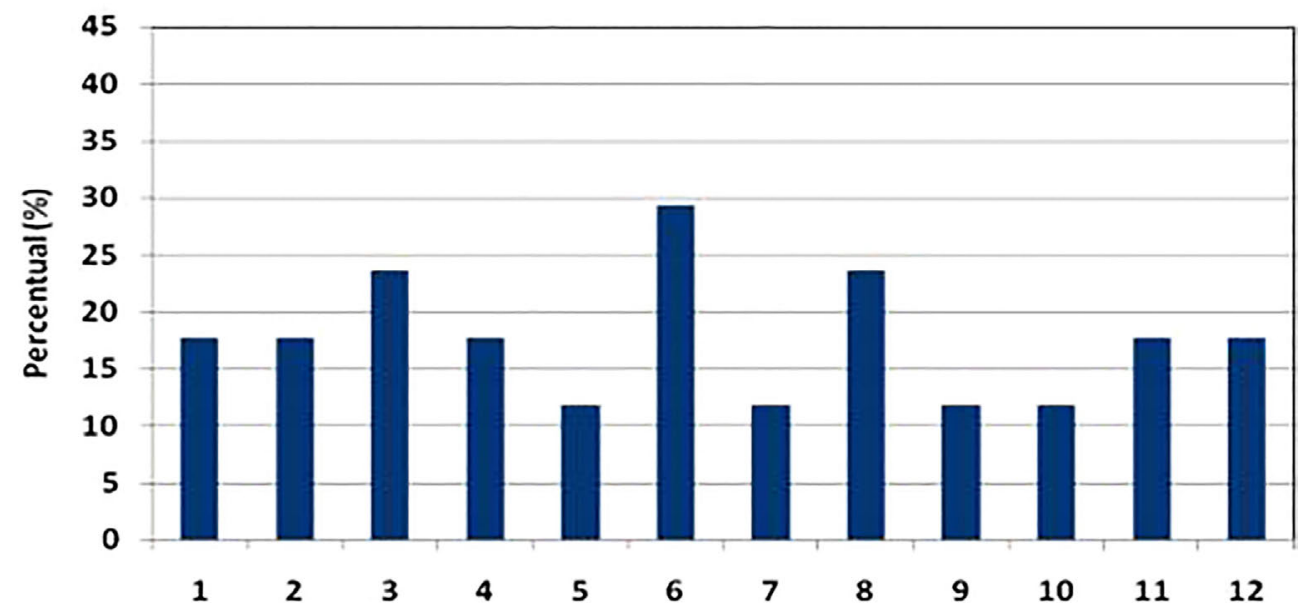

Figura 3h - Percentual mensais de condições favoráveis (anomalia umidade do solo negativa) entre 2002-2018 para ocorrência de focos de calor anuais no bioma Caatinga.

sentativa do bioma mencionada na seção de metodologia.

As Figs. 4 e 5 mostram a correlação espacial de algumas variáveis atmosféricas e na superfície do bioma Caatinga com o número médio de focos de calor detectados por satélites. Essas correlações referem-se às duas estações juntas, duas mais chuvosas (verão e outono) e secas (inverno e primavera) na Caatinga.

Para as estações de verão e outono as variáveis que apresentaram áreas com correlação significativa estatisticamente a 95\% segundo teste t Student com os focos de calor médios no bioma Caatinga foram a precipitação e temperatura e umidade do solo (Fig. 4).

Pose-se notar por essas Figs. 4a, 4b e 4c que fisicamente o sinal das correlações é consistente com valores negativos variando-os de 0,05 a 0,45 em algumas áreas do bioma. Essas correlações inferiram que menos precipitação e menor umidade e temperatura do solo no bioma o número de focos de calor é menor. Áreas com correlações mais significativas apareceram espalhadas para as variáveis precipitação e umidade no solo, em geral, localizando-se mais para as áreas ao norte do bioma. Essas características mostraram que nesses anos de 2002-2018 essas variáveis nessas áreas estiveram mais favoráveis as ocorrências, em média, aos focos de calor observados no setor norte bioma Caatinga do que áreas mais ao sul do bioma.

Para as duas estações mais secas (inverno e primavera) no bioma Caatinga as correlações com as variáveis são mostradas na Fig. 5. Como observado na Fig. 4 as correlações são consistentes fisicamente, com valores negati- a) $r-P \cos x \operatorname{Prp}$

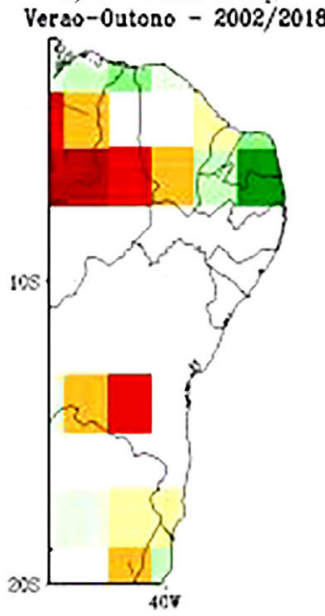

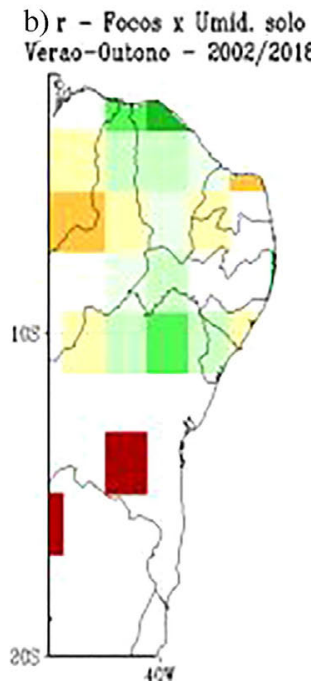

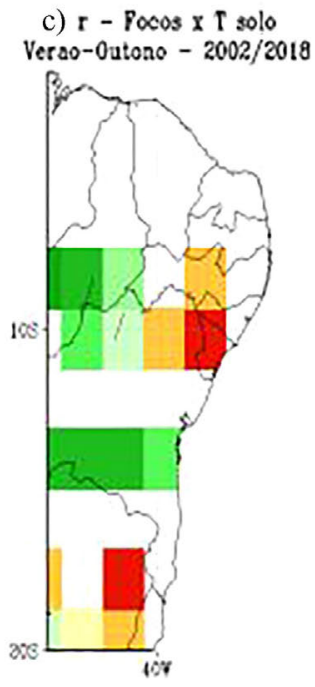

$-0.05$

$-0.09$

$-0.15$

$-0.18$

$-0.21$

$-0.24$

$-0.27$

$-0.3$

$-0.33$

$-0.38$
$-0.1$

$-0.15$

$-0.2$

$-0.25$

$-0.3$

$-0.35$

$-0.4$

$-0.45$

Figura 4 - Correlação de Pearson entre focos de calor e variáveis meteorológicas no bioma Caatinga (2002-2018). a) precipitação, b) umidade no solo e c) temperatura do solo. Nas figuras são apenas mostradas as áreas com significância estatística a 95\% segundo teste t Student. 
vos indicando que precipitação, temperatura e umidade abaixo da média, estiveram associadas ou estão a focos de calor mais expressivos no bioma Caatinga. As magnitudes da correlação foram maiores nessas duas estações com a temperatura do solo, e houve uma extensão em área para o sul do bioma com a precipitação.

A Tabela 7 mostra a correlação mensal de Pearson entre as variáveis meteorológicas, valores médios dos pontos de grade inseridos na área do bioma Caatinga defi- nido na seção de metodologia, e os focos de calor mensais e sazonais (estações do ano) no período de 2002-2018.

Pode-se ser observado por essa Tabela 7 que as correlações variaram de magnitudes para os meses e estações com todas as variáveis. O ideal fisicamente seria que as correlações com precipitação, umidade e umidade do solo e relativa do ar fossem negativas e positivas com as temperaturas e radiação a superfície. Porém, não se observa essa linearidade tanto nos meses como nas estações do
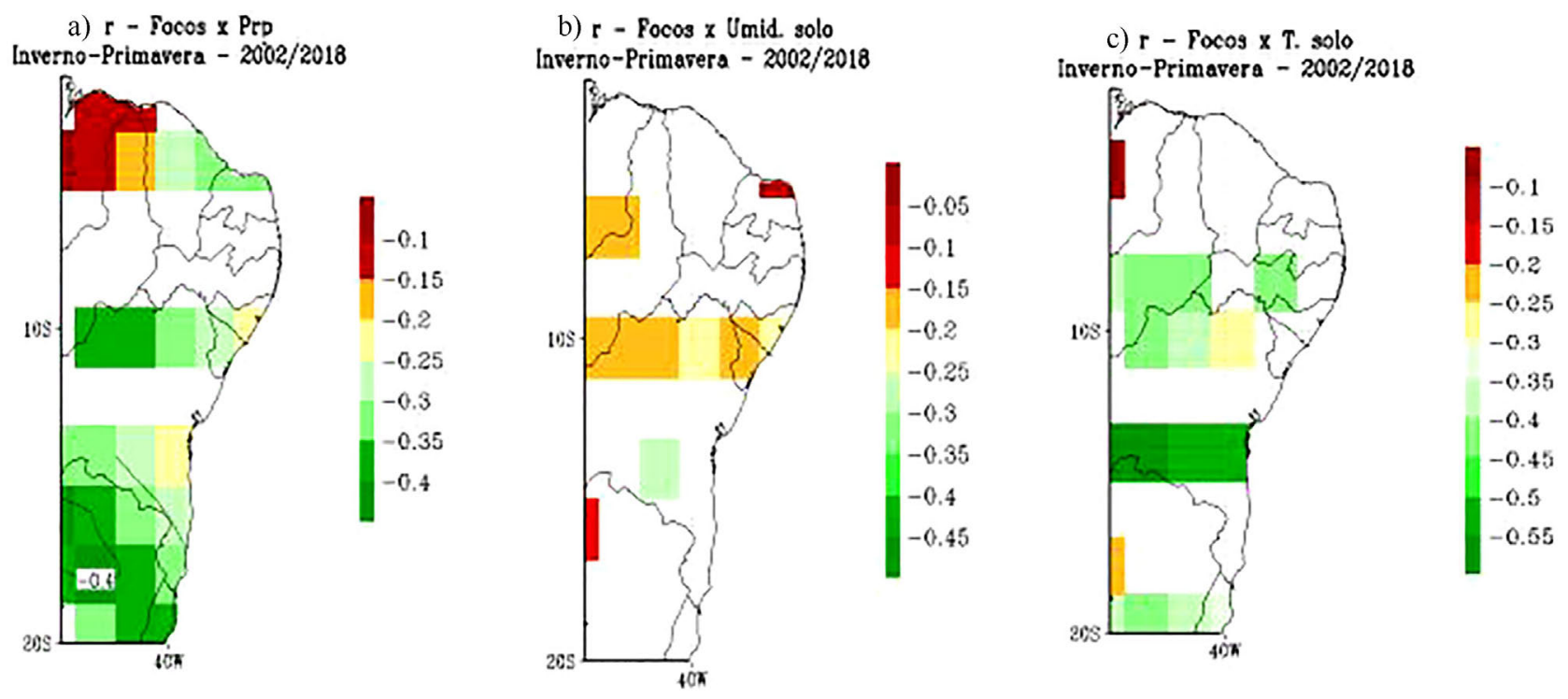

Figura 5 - Correlação de Pearson entre focos de calor e variáveis meteorológicas no bioma Caatinga (2002-2018). a) precipitação, b) umidade no solo e c) temperatura do solo. Nas figuras são apenas mostradas as áreas com significância estatística a 95\% segundo teste t Student.

Tabela 7 - Correlação mensal e sazonal (2002-2018) de Pearson entre as variáveis meteorológicas, valores médios dos pontos de grade. Tar (temperatura do ar), Prp (precipitação), Ur (umidade relativa do ar), Etp (evapotranspiração), Rad (radiação a superfície), T solo (temperatura do solo) e Umid Solo (umidade do solo).

\begin{tabular}{|c|c|c|c|c|c|c|c|c|}
\hline & Tar & Prp & Vento & $\mathrm{Ur}$ & Etp & $\mathrm{Rad}$ & Tsolo & Umd. Solo \\
\hline JAN & -0.18 & -0.31 & -0.12 & -0.22 & -0.22 & -0.20 & -0.03 & 0.03 \\
\hline FEV & -0.37 & 0.06 & 0.28 & 0.09 & -0.14 & 0.04 & -0.22 & -0.24 \\
\hline MAR & -0.10 & -0.11 & 0.25 & -0.01 & -0.28 & -0.50 & 0.20 & -0.04 \\
\hline ABR & 0.13 & -0.36 & 0.06 & 0.23 & 0.00 & -0.34 & 0.15 & -0.20 \\
\hline MAI & -0.31 & 0.21 & 0.19 & 0.26 & -0.05 & -0.08 & 0.18 & -0.06 \\
\hline JUN & 0.07 & 0.05 & 0.33 & -0.30 & 0.05 & 0.01 & -0.17 & 0.35 \\
\hline JUL & -0.19 & 0.39 & -0.11 & 0.08 & -0.34 & 0.46 & -0.28 & 0.26 \\
\hline $\mathrm{AGO}$ & -0.34 & 0.42 & -0.02 & 0.26 & -0.30 & 0.12 & -0.38 & -0.19 \\
\hline SET & -0.48 & 0.08 & 0.51 & 0.13 & -0.55 & -0.24 & 0.12 & -0.20 \\
\hline OUT & -0.23 & -0.25 & 0.09 & 0.31 & 0.12 & 0.12 & -0.16 & -0.21 \\
\hline $\mathrm{NOV}$ & -0.24 & 0.08 & -0.18 & 0.23 & -0.23 & -0.09 & 0.15 & -0.22 \\
\hline DEZ & -0.13 & -0.10 & -0.11 & -0.32 & 0.44 & 0.01 & -0.06 & -0.23 \\
\hline Verão & -0.40 & $-0,29$ & -0.20 & -0.30 & -0.68 & 0.43 & -0.23 & -0.24 \\
\hline Outono & -0.03 & -0.41 & -0.37 & 0.18 & -0.30 & 0.01 & 0.08 & -0.25 \\
\hline Inverno & 0.15 & 0.03 & -0.20 & 0.03 & 0.10 & 0.26 & -0.11 & -0.26 \\
\hline Primavera & -0.28 & -0.26 & 0.34 & 0.25 & -0.27 & 0.66 & -0.08 & -0.27 \\
\hline
\end{tabular}


ano. Essas correlações fora de fase fisicamente com os focos de calor podem ser devido aos dados de temperatura do ar, de reanálises, que devem não ter uma resolução espacial adequada para representar essas variáveis para área do bioma Caatinga. Para o mês de setembro a temperatura, velocidade do vento e evapotranspiração mostraram valores de magnitudes de correlação mais altos com os focos de calor, valores em negrito na Tabela 7 .

\section{4. Índice de focos de incêndio inferido por variáveis atmosféricas}

A seção em análise infere resultados do IRFI sazonais (estações do ano, média para 2002-2018) no bioma em estudo usando as variáveis meteorológicas, vento e umidade relativa seus valores médios em pontos de grade na área do bioma Caatinga dado pelo índice mostrado na seção de metodologia.

A Fig. 6 mostra as áreas em que a condição assumida para o cálculo do IRFI foi detectada nas estações de verão, outono, inverno e primavera sobre a área do bioma Caatinga.

Observou-se que em todas as estações, no bioma Caatinga, o índice variou com valores entre 12 a 36, segundo a classificação do índice de Monte Alegre modificado, esses valores se enquadram em um risco médio $(8,1$ a 14) e alto (14,1 a 24), sendo que no setor leste da região Nordeste pode-se observar pequenas áreas com risco muito alto (acima de 24) na estação de outono. Áreas mais vulneráveis a esse risco foram as do setor norte do bioma, incluindo grande parte do Estado do Ceará e setor leste do Nordeste.

Para a estação de inverno os riscos de focos de calor aumentaram em áreas do leste do Nordeste, com classificação de alto risco, valores superiores a 24, incluindo parte do leste do Ceará. Na estação da primavera, apesar de ser a estação mais seca no bioma Caatinga, e nos dados observados ser a estação de maior número de focos de calor, esse índice de risco mostrou valores associados à riscos classificados como médios, com pequenas áreas no bioma.

Algumas discussões sobre focos de calor (calor) e condições atmosféricas e ambientais podem ser endereçadas. No que se refere a mudanças climáticas, embora a série de dados observada por satélites dos focos de calor (calor), ter um curto período em anos de 2002-2018, os últimos anos mostraram um decréscimo nesse número. Porém, estudos que inferiram um índice de focos de calor usando dados de cenários de temperatura e umidade relativa do ar com dados RCP4,5 e RCP8,5 relatados no Intergovernmental Panel on Climate Change (IPCC), mostraram que esses focos poderão ter um pequeno aumento no bioma Caatinga comparados aos observados atualmente (Silva et al., 2018).

Os resultados não implicam insignificância da velocidade do vento ou da temperatura do ar a superfície sobre os focos de calor e, sim, que para analisar suas influências mais diretas se devem buscar métodos mais adequados de análises e dados medidos no bioma Caatinga que sejam mais representativos de suas variabilidades.

Os resultados inferiram, ainda, para a importância da influência dos elementos meteorológicos sobre a umidade do material combustível. De acordo com Nunes et al. (2015), a umidade do material combustível expressa a porcentagem de água que ele contém, em relação ao seu peso seco.

Nunes et al. (2015) afirmaram ainda que a umidade atmosférica é elemento decisivo nos incêndios florestais, tendo efeito direto na inflamabilidade dos combustíveis florestais, havendo troca constante de umidade entre a atmosfera e esses combustíveis.

O período de seca (julho-dezembro) apresentou o maior número de queimadas e de focos de calor no bioma
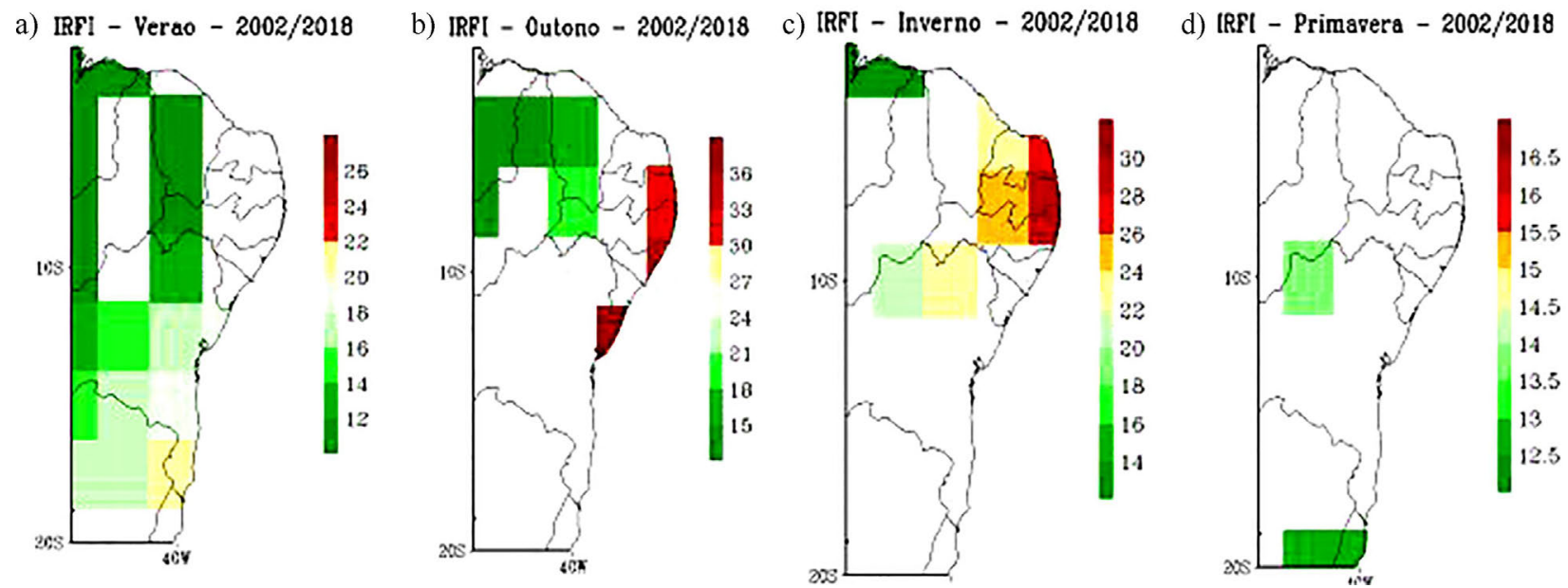

Figura 6 - IRFI inferido por variáveis meteorológicas no bioma Caatinga (2002-2018). verão, b) outono, c) inverno e d) primavera. Nas figuras são apenas mostradas as áreas que passaram no teste do cálculo do índice (pontos de grade com precipitação na estação menor que $5 \mathrm{~mm} / \mathrm{dia}$ ). 
Caatinga, porém não se observou no IRFI apresentados. O aumento de queimadas ou focos de calor nos meses iniciais do ano, no período de La Niña pode estar associado à expectativa que o agricultor possui de uma boa quadra chuvosa para plantar há uma tradição de queimar sua vegetação seca e desgastada da seca no semestre anterior. Essa biomassa seca é de fácil combustão por apresentar alto índice de inflamabilidade, sobretudo, quando associada com elevada temperatura e baixa umidade relativa do ar (Nobre et al., 2007). As condições climáticas e incêndios mantêm uma estreita relação, desde a probabilidade de ocorrências de incêndios decorrente das condições atmosféricas em um dado período de tempo, até a manutenção e propagação do fogo (Torres et al., 2010). Índices de risco de incêndio possibilitam aos setores de prevenção e combate aos incêndios uma avaliação.

\section{Conclusões e Considerações Finais}

Os últimos anos, a partir de 2010, mostraram um decréscimo no número de focos de calor. Porém, estudos que inferiram um índice de focos de calor usando dados de cenários de temperatura e umidade relativa do ar com dados RCP4,5 e RCP8,5 do IPCC, mostraram que esses focos poderão ter um pequeno aumento no bioma Caatinga comparados aos observados atualmente (Silva et al., 2016). Essa diminuição pode estar associada às práticas de prevenção implantadas pelas Defesas Civis Municipais e Estaduais.

Ressalta-se, que os resultados não implicaram insignificância da velocidade do vento ou da temperatura do ar a superfície sobre os focos de calor e, sim, que para analisar suas influências mais diretas se devem buscar métodos mais adequados de análises e dados medidos no bioma Caatinga em escalas temporais como diários ou horários que sejam mais representativos de suas variabilidades comparadas ao inicio dos focos de calor.

Observou-se que nas medidas de tendência central, para todos os anos, exceto nos anos Neutros, o mês de janeiro apresentou um acentuado número de focos de calor, maior que a média histórica, o que nos permitiu sugerir maior atenção dos órgãos de controle ambiental e Corpos de Bombeiros, com trabalhos preventivos às queimadas para esse mês em questão.

Os resultados ainda inferiram, para a importância da influência dos elementos meteorológicos sobre a umidade do material combustível. De acordo com Nunes et al. (2015), a umidade do material combustível expressa a porcentagem de água que ele contém, em relação ao seu peso seco. Nunes et al. (2015). Esses autores afirmaram ainda que a umidade atmosférica é elemento decisivo nos incêndios florestais, tendo efeito direto na inflamabilidade dos combustíveis florestais.
O período de seca (julho-dezembro) apresentou o maior número de queimadas e de focos de calor no bioma Caatinga, porém não se observou nos IRFIs apresentados.

Nunes et al. (2015) afirmaram ainda que a umidade atmosférica é elemento decisivo nos incêndios florestais, tendo efeito direto na inflamabilidade dos combustíveis florestais, havendo troca constante de umidade entre a atmosfera e os combustíveis mortos.

As condições climáticas e incêndios mantêm uma estreita relação, desde a probabilidade de ocorrências de incêndios decorrente das condições atmosféricas em um dado período de tempo, até a manutenção e propagação do fogo (Torres et al., 2010).

Para estudos futuros sugere-se usar dados de variáveis meteorológicas de outras fontes de reanálises e outros períodos como diários ou até horários, e se possíveis medidas no bioma Caatinga e fazer relações simultâneas e defasadas com esses focos de calor e calcular novos índices de calor disponíveis na literatura (Machado et al., 2014), e também comparar esses índices com o uso de variáveis meteorológicas projetadas pelos modelos analisados nos estudos avaliados pelo IPCC.

Quanto aos números de dados existentes há de se analisar a necessidade dos órgãos competentes para uma maior interferência positiva para o acréscimo de estações meteorológicas, a fim de estratificar mais os dados pelo Bioma e assim ofertar mais condições em estudos futuros.

\section{Agradecimentos}

Ao INPE pela disponibilidade dos dados de focos de calor e a NOAA pelos dados usados nesse estudo. Análises e resultados desse artigo são da Dissertação de Mestrado do primeiro autor, Francisco Carlos de Araújo, apresentada no Mestrado Profissional em Climatologia e Aplicações na Comunidade dos Países de Língua Portuguesa (CPLP) e África da Universidade Estadual do Ceará.

\section{Referências}

ALMEIDA, I.J. Análise de Riscos de Incêndio em Espaços Urbanos Revitalizados: Uma Abordagem no Bairro de Recife. Dissertação de Mestrado em Engenharia de Produção, UFPE, 2002.

ARAÚJO FILHO, J.A.; BARBOSA, T.M.L. Manejo agroflorestal de Caatinga: uma proposta de sistema de produção. In: OLIVEIRA, T.S.; ASSIS JUNIOR, R.N.; ROMERO, R.E.; SILVA, J.R.C. Agricultura, Sustentabilidade e o Semi-Árido. Fortaleza: UFC, 2000.

BONITESE, K.V. Segurança Contra Incêndio em Edifício Habitacional de Baixo Custo Estruturado em Aço. Dissertação de Mestrado em Construção Civil, Universidade Federal de Minas Gerais, 253 p., 2007.

BOWMAN, D.M.; BALCH, J.K.; ARTAXO, P.; BOND, W.J.; CARLSON, J.M. Fire in the earth system. Science, v. 324, p. 481-484, 2009. 
DEPPE, F.; PAULA, E.V.; MENEGHETTE, C.R.; VOSGERAU, J. Comparação de índice de risco de incêndio florestal com focos de calor no Estado do Paraná. Floresta, v. 34, n. 2, p. 119-126, 2004.

DOERR, S.H.; SANTIN, C. Global trend in wild fires and its impacts perceptions versus realities in changing world. Phil. Trans. R. Soc. B, v. 371, n. 20150345, p. 1-10, 2016.

GRANEMANN, D.C.; CARNEIRO, G.L. Monitoramento de focos de incêndio e áreas focos de incêndios com utilização de imagens de sensoriamento remoto. Revista de Engenharia e Tecnologia, v. 1, n. 1, p. 55-62, 2009.

INPE. Mapa do Fogo. Disponível em http://queimadas.dgi.inpe. br/queimadas/portal/risco-de-fogo-meteorologia, acessado em 22/09/2019.

IPEA. O Custo Econômico Do Fogo Na Amazônia, 2002 Disponível em http://www.ipea.gov.br/portal/images/stor ies/PDFs/TDs/td_0912.pdf.

E. KALNAY; M. KANAMITSU; R. KISTLER; W. COLLINS; D. DEAVEN; L. GANDIN; KALNAY, E.; KANAMITSU, M.; KISTLER, R.; COLLINS, W.; DEAVEN, D.; GANDIN, L. et al. The NCEP/NCAR 40-year Reanalysis Project. Bulletin of the American Meteorological Society, v. 77, n. 3, p. 437-471, 1996.

MACHADO, N.G.; SILVA, F.C.P.; BIUDES, M.S. Efeito das condições meteorológicas sobre o risco de incêndio e o número de focos de incêndios urbanas e focos de calor em Cuiabá-MT, Brasil. Ciência e Natura, v. 36 n. 3, p. 459469, 2014.

MACIEL, B.A. Unidades de conservação no bioma Caatinga. In: GARIGLIO, M.A.; SAMPAIO, E.V.S.; CESTARO, L.A.; KAGEYAMA, P.Y. (orgs.) Uso Sustentável e Conservação Dos Recursos Florestais Da Caatinga. Brasília: Ministério do Meio Ambiente/Serviço Florestal Brasileiro, 2010.

NOBRE, P.; SHUKL, J. Variations of sea surface temperature, wind stress, and rainfall over the tropical Atlantic and
South America, Journal of Climate, v. 9, n. 10, p. 24642479, 1996.

NOBRE, C.A.; SAMPAIO, G.; SALAZAR, L. Mudanças climáticas e Amazônia. Ciência e Cultura, v. 59, n. 3, p. 22-27, 2007.

NUNES, M.T.O.; SOUSA, G.M.; TOMZHINSKI, G.W.; OLIVEIRA-JÚNIOR, J.F.; FERNANDES, M.C. Factors Influencing on Susceptibility Forestry Fire in Itatiaia National Park. Anuário do Instituto de Geociências, v. 38, n. 1, p. 54-62, 2015.

RODRIGUES R.R.; MCPHADEN, M.J. Why did the 2011-2012 La Niña cause a severe drought in the Brazilian Northeast? Geophys Res Lett, v. 41, n. 3, p. 1012-1018, 2014.

SILVA, P.; BASTOS, A.; Da Camara, C.C.; Libonati, R. Future projections of fire occurrence in Brazil using EC-Earth climate model. Revista Brasileira de Meteorologia, v. 31, n. 3. p. 288-297, 2016.

TORRES, F.T.P.; RIBEIRO, G.A.; MARTINS, S.V., LIMA, G.S. Determinação do período mais propício às ocorrências de incêndios em vegetação na área urbana de Juiz de Fora, MG. Árvore, v. 34, n. 2, p. 297-303, 2010.

UVO, C.B.; REPELLI, C.A.; ZEBIAK, S.E. Relationship between tropical Pacific and Atlantic SST and northeast Brazil monthly precipitation. Journal of Climate, v. 11, n. 4, p.551-562, 1998.

\section{Endereços da Internet}

http://www.inpe.br/focosdeincêndios/portal https://www.esrl.noaa.gov/psd/data/climateindices/list/

License information: This is an open-access article distributed under the terms of the Creative Commons Attribution License (type CC-BY), which permits unrestricted use, distribution and reproduction in any medium, provided the original article is properly cited. 